\title{
Effect of Temperature and Bake-out on Formaldehyde Emission from UF Bonded Wood Composites*1
}

\author{
Young-Kyu Lee ${ }^{* 2,3}$ and Hyun-Joong Kim ${ }^{* 3,4}+$
}

\begin{abstract}
This study analysis the effect of various temperatures $\left(20,35\right.$ and $\left.50^{\circ} \mathrm{C}\right)$ on the formaldehyde emission from wood composites, which were particleboard (PB), medium density fiberboard (MDF), high density fiberboard (HDF) and laminated HDF (L-HDF) by Japanese desiccator method. Also, to reduce formaldehyde emission by wood composites, it has been suggested that undergo a bake-out conditions. On average, the level of formaldehyde emission increased many times with a $15^{\circ} \mathrm{C}$ increase in temperature from 20 to $35^{\circ} \mathrm{C}$ for $\mathrm{PB}, \mathrm{MDF}, \mathrm{HDF}$ and L-HDF, respectively. Formaldehyde emissions from wood composites could be expected to increase with increasing ambient temperature. At $35^{\circ} \mathrm{C}$ for 28 days bake-out treatment of boards, the free formaldehyde emission reduced $67.8 \%$ (PB), $40.1 \%$ (MDF), 37.8\% (HDF), and $35.2 \%$ (L-HDF). On the other hand, after the bake-out at $50^{\circ} \mathrm{C}$ for 28 days, the formaldehyde concentration decreased by $88.2,66.9,62.2$ and $59.3 \%$ of the concentration before the bake-out for PB, MDF, HDF and L-HDF, respectively. An interesting of the bake-out treatment at $50^{\circ} \mathrm{C}$ after 14 days, formaldehyde emission grade of $\mathrm{PB} \& \mathrm{MDF}$ down $\mathrm{E}_{2}$ to $\mathrm{E}_{1}$, and $\mathrm{HDF} \& \mathrm{~L}-\mathrm{HDF}$ down $\mathrm{E}_{1}$ to $\mathrm{E}_{0}$.
\end{abstract}

Keywords : wood composites, formaldehyde emission, bake-out treatment, desiccator method

\section{INTRODUCTION}

Wood composites are used in all aspects of house construction, including house interior decoration boards. In modern housing, a majority of indoor surfaces are made from composite wood materials. Wood products such as furniture, flooring and building materials may emit a variety of volatile organic compounds (VOCs) into the indoor air environment. The formaldehyde emission from indoor materials and wood composites is influenced by temperature. The three controlling processes for emissions: the diffusion within the material to the surface, the desorption from the surface, and the evaporation from the surface, all increase with the

*1 Received on January 30, 2012; accepted on March 20, 2012

*2 Indoor Air Quality Analysis Center, National Instrumentation Center for Environmental Management, Seoul National University, Seoul 151-921, Korea

*3 Laboratory of Adhesion and Bio-Composites, Program in Environmental Materials Science, Seoul National University, Seoul 151-921, Korea

*4 Research Institute for Agriculture and Life Sciences, Seoul National University, Seoul National University, Seoul 151-921, Korea

† Corresponding author : Hyun-Joong Kim (e-mail: hjokim@snu.ac.kr) 
temperature quantitatively[1]. Increased temperature may also accelerate chemical reactions within the material, leading to additional formaldehyde emissions. Therefore, the temperature has a major impact on the formaldehyde emission from indoor materials and wood composites.

The ONDOL floor heating system has been used conventionally in Korea since 400 B.C.[2]. After the 1970s, residential buildings were developed as high-rise apartments. The ONDOL system was modernized, with a gas boiler installed instead of using forest and briquette fuel .Hot water from a boiler is supplied to the floor coil, which is the X-L pipe underneath the floor surface. The thermal storage mass was put in place of the stone slab as mortar. The principle of the ONDOL floor heating system has remained the same, even as its form has changed. At the floor surface, heat is radiated to warm up the air temperature, and consequently, keeping the human body warm. Koreans enjoy using this ONDOL floor heating system. Koreans spend most of their time sitting on ONDOL floors, with their buttocks always in contact with the floor surface. The recommended floor surface temperature was at the range of $19 \sim$ $26^{\circ} \mathrm{C}$. Nonetheless, floor heating systems can set the maximum floor surface temperature up to $29 \sim 32^{\circ} \mathrm{C}[3]$. Although indoor air temperatures are generally limited to a range between 17 and $25^{\circ} \mathrm{C}$, floor heating could create exceptionally hot conditions in flooring materials with temperatures of $40 \sim 50^{\circ} \mathrm{C}$.

To prevent building-associated complaints caused by VOC off-gassing from residual solvents in new building materials and furnishings, a procedure known as a "bake-out" has been used to reduce VOC emissions from newly installed materials, products, and furnishings[4,5]. The principle of this procedure is to drive VOCs out of materials into indoor air by raising the temperature in the building up to a level of $32 \sim 40^{\circ} \mathrm{C}$, while increasing outdoor air exchange so that emissions are removed from the building. In this procedure, the air temperature in the unoccupied but fully furnished building is elevated while some ventilation is maintained.

This procedure should increase the vapor pressure of the residual solvents during the bake-out and, if done long enough, could deplete these solvents, subsequently reducing the VOC emissions. Only fragmentary evidence exists to suggest the practicality of this method and to provide guidance regarding the time, temperature, and ventilation rate necessary to be effective.

This study analyses the effect of various indoor temperatures in under floor heating system on the formaldehyde emission from wood composites using a Japanese desiccator test. Also, the results from this building bake-out suggest that the procedure may have merited, more information is needed to demonstrate this and to optimize the time and temperature of this treatment.

\section{MATERIAL and METHODS}

\subsection{Materials}

There are four specific types of wood composites: particle board (PB), medium density fiberboard (MDF), high density fiberboard (HDF) and laminated HDF (L-HDF). After investigation of product information and the use of pressed wood products indoors, four different composite wood products were selected.

$\mathrm{E}_{2}$ grade UF resin bonded PB $15 \mathrm{~mm}$ thickness was used, having a density of $630 \mathrm{~kg} / \mathrm{m}^{3}$. $\mathrm{PB}$ is suitable for interior use in a wide variety of furniture and joinery assemblies and particularly as shelving, in cupboards, wardrobes and wall units. 

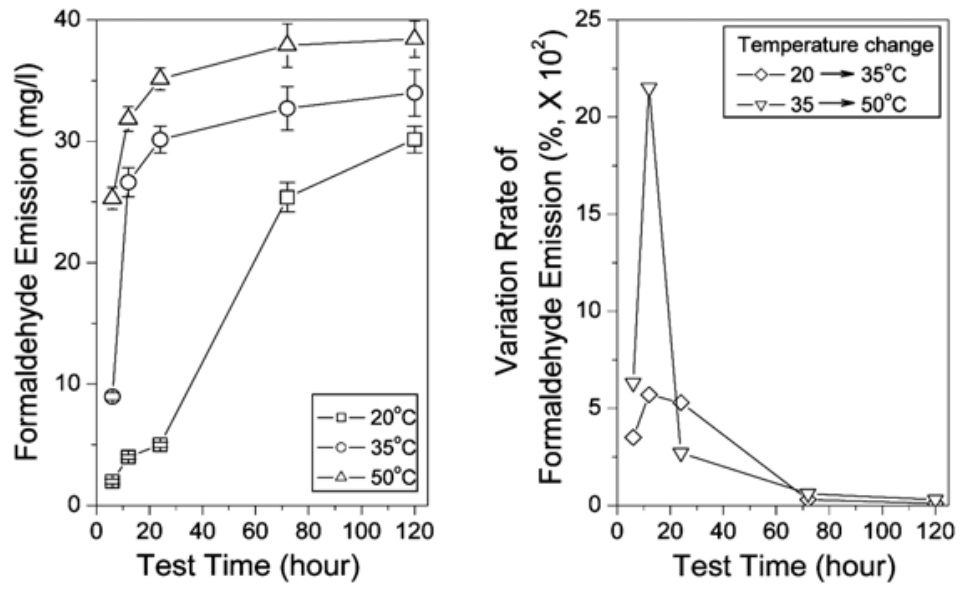

Fig. 1. Effect of temperature and time on formaldehyde emission from PB.

$\mathrm{E}_{2}$ grade UF resin bonded $\mathrm{MDF} 15 \mathrm{~mm}$ thickness was used, having a density of 610 $\mathrm{kg} / \mathrm{m}^{3}$. MDF is commonly used as decorative panelling, and has further decorative uses in furniture and structural uses in joinery.

$\mathrm{E}_{1}$ grade UF resin bonded HDF $8 \mathrm{~mm}$ thickness was used, having a density of $1,000 \mathrm{~kg} / \mathrm{m}^{3}$. HDF is used as flooring material support.

HDF laminated on both sides with low-pressure, melamine-impregnated decorative paper is abbreviated L-HDF. The thickness was $8 \mathrm{~mm}$ and the density was $1,110 \mathrm{~kg} / \mathrm{m}^{3}$. L-HDF is used as flooring material.

\subsection{Methods}

\subsubsection{Determination of Formaldehyde Emi- ssion (Desiccator Method)}

The Japanese standard method (JIS A 1460) is a $24 \mathrm{~h}$ desiccator test. Emission of formaldehyde is determined by placing test pieces of known surface area in a desiccator at a controlled temperature and measuring the quantity of emitted formaldehyde absorbed in a specified volume of water during $24 \mathrm{~h}[6]$.

The interior volume of the desiccator was about 10 liter and $5 \times 15 \mathrm{~cm}$ specimens were used for each desiccator test. The specimens were cut from sample panel of panel parts to obtain adequate distribution of area within the panel or parts. The specimens were then conditioned stored on edge, spaced apart, so that air could freely circulate across all surfaces for seven days at $20 \pm 1.5^{\circ} \mathrm{C}$ and $50 \pm 10 \%$ relative air humidity. The sample total surface area was $1,800 \mathrm{~cm}^{2}$. The released formaldehyde was caught in the distilled water, which was analyzed using a UV spectrophotometer, after treatment with acetyl acetone and acetyl acid ammonium.

\subsubsection{Effect of Temperature and Time on Formaldehyde Emission in Desic- cator Method}

Five desiccators containing the samples were then maintained at a constant temperature of $20^{\circ} \mathrm{C}$ and measuring the quantity of emitted formaldehyde absorbed in a specified volume of water during 6, 12, 24, 72 and 120 h. At 35 and $50^{\circ} \mathrm{C}$, experiments were conducted under the same conditions. 

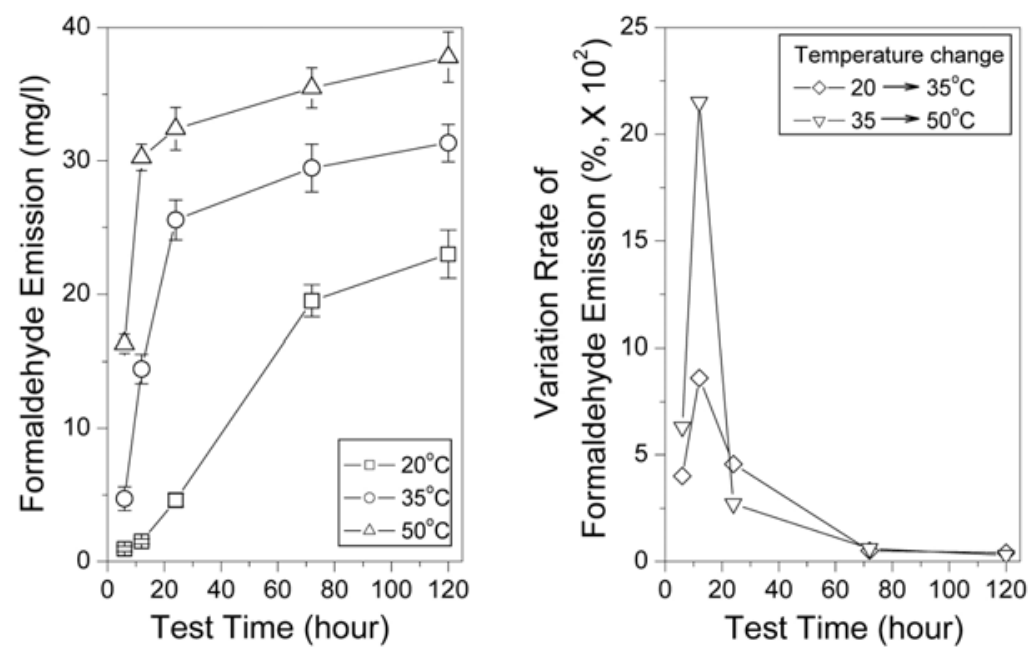

Fig 2. Effect of temperature and time on formaldehyde emission from MDF.

\subsubsection{Bake-out Procedure}

The formaldehyde emission was tested before, during, and after the bake-out. The samples were baked out for $1,3,5,7,10,14,21$, and 28 days temperatures of $20 \pm 2,35 \pm 2$, and $50 \pm 2{ }^{\circ} \mathrm{C}$ in adry oven. After bake-out processing, the specimens were conditioned for 2 weeks at $20 \pm 2^{\circ} \mathrm{C}$ and $50 \pm 3 \%$ relative air humidity. Then the free formaldehyde emission was tested by desiccator method.

\section{RESULTS and DISCUSSION}

\subsection{Effect of Temperature and Time on Formaldehyde Emission}

The results obtained for PB are presented in Fig. 1. The formaldehyde emission was rapidly increased with the test duration. At $20^{\circ} \mathrm{C}$ after $72 \mathrm{~h}$ it reached $25.4 \mathrm{mg} / \ell$. The initial emission level was about 12 times lower. The results obtained at 35 and $50^{\circ} \mathrm{C}$ showed that the formaldehyde emission was rapidly increased with test duration between 6 and $24 \mathrm{~h}$, but then re- mained relatively stable for a test duration over $24 \mathrm{~h}$. The formaldehyde emission increases appreciably with increasing temperature.

At $6 \mathrm{~h}$, the formaldehyde emission was 2.0, 9.0 and $25.3 \mathrm{mg} / \ell$ at 20,35 and $50^{\circ} \mathrm{C}$. At 24 $\mathrm{h}$, which is the standard time of the desiccator method, the formaldehyde emission level at $20^{\circ} \mathrm{C}$ was $5 \mathrm{mg} / \ell$ and at $35^{\circ} \mathrm{C}$, was $30.2 \mathrm{mg} /$ $\ell$. A temperature change from 20 to $35^{\circ} \mathrm{C}$, the emission level increase 6 times. Above this temperature range, the effect was more pronounced.

Fig. 2 shows the same tendency for MDF. A low emission level was observed at $20^{\circ} \mathrm{C}$ and $24 \mathrm{~h}$. The increase of temperature up to $35^{\circ} \mathrm{C}$ induced a rapidly increased in the initial emission and temperature increase up to $50^{\circ} \mathrm{C}$ sharply increased the formaldehyde emission. Furthermore, the formaldehyde emission increase rate was higher than that of $\mathrm{PB}$.

The formaldehyde emission levels from HDF and L-HDF are depicted in Figs. 3 and 4. Low emission levels were observed at the test duration of 6 and $24 \mathrm{~h}$ at $20^{\circ} \mathrm{C}$, but were higher at $35^{\circ} \mathrm{C}$ and much higher at $50^{\circ} \mathrm{C}$. Particularly, the 
Effect of Temperature and Bake-out on Formaldehyde Emission from UF Bonded Wood Composites
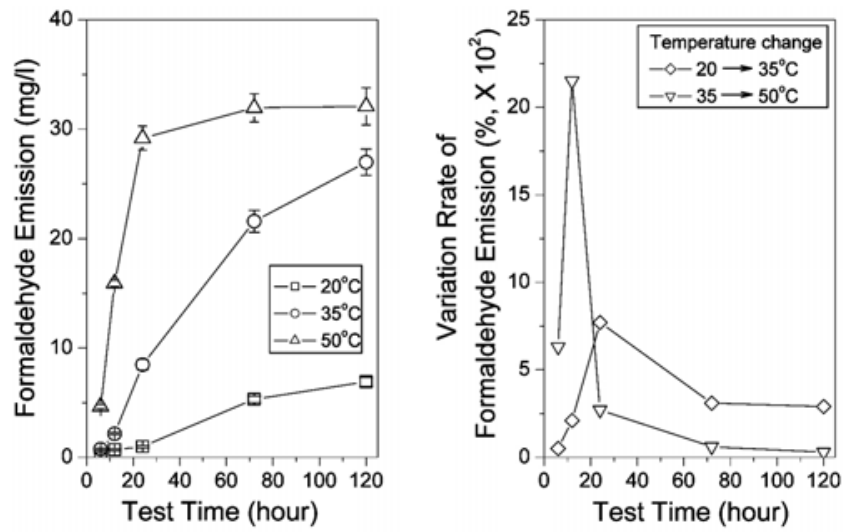

Fig. 3. Effect of temperature and time on formaldehyde emission from HDF.
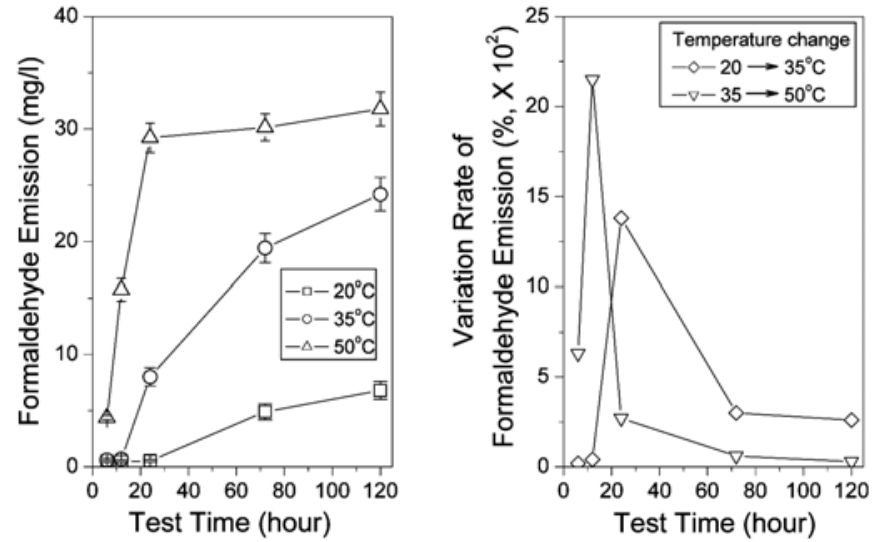

Fig. 4. Effect of temperature and time on formaldehyde emission from L-HDF.

formaldehyde emission at 24 hour showed a distinct difference between the temperatures.

Low and constant emission levels of $0.5 \mathrm{mg} /$ $\ell$ were observed from L-HDF at $20^{\circ} \mathrm{C}$ for 6 , 12 , and $24 \mathrm{~h}$, respectively. The increase of temperature to 35 and $50^{\circ} \mathrm{C}$ induced formaldehyde emission from L-HDF. The source of the emission might have been the HDF substrate. According to this result, the laminated surface had no effect on reducing the formaldehyde emission at high temperature.

Generally, flooring is manufactured using $\mathrm{E}_{1}$ grade UF resin in Korea. HDF are made by urea-formaldehyde resin or urea-melamine-formaldehyde condensed resin. On the other hand, $\mathrm{PB}$ and MDF used as furniture materials coated with decoration film, belong to the formaldehyde emission class $\mathrm{E}_{2}$ grade. Therefore, formaldehyde emission of 5.0, 4.6, 1.0 and 0.5 $\mathrm{mg} / \ell$ were observed from $\mathrm{PB}, \mathrm{MDF}, \mathrm{HDF}$ and $\mathrm{L}-\mathrm{HDF}$ at $20^{\circ} \mathrm{C}$ for $24 \mathrm{~h}$, respectively.

Although indoor air temperatures are generally limited to a range between 17 and $25^{\circ} \mathrm{C}$, floor heating could create exceptionally hot con- 

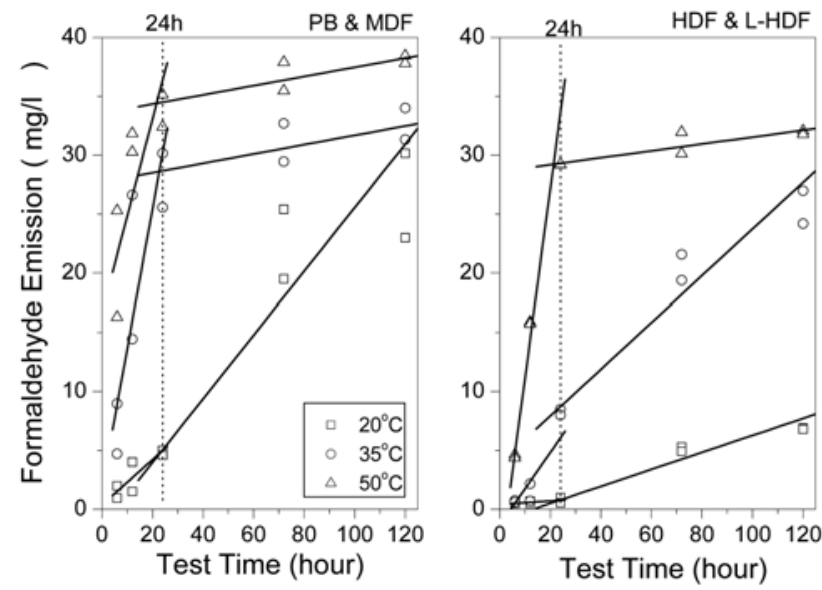

Fig. 5. Correlation between formaldehyde emission and temperature of the composites.

Table 1. Result of correlation between formaldehyde emission and temperature of the composites

\begin{tabular}{|c|c|c|c|}
\hline Composites & Test Temperature $\left({ }^{\circ} \mathrm{C}\right)$ & $\begin{array}{l}\text { Test Duration } \\
6 \mathrm{~h} \sim 24 \mathrm{~h}\end{array}$ & $\begin{array}{l}\text { Test Duration } \\
24 \mathrm{~h} \sim 120 \mathrm{~h}\end{array}$ \\
\hline \multirow{3}{*}{$\mathrm{PB} \& \mathrm{MDF}$} & 20 & $\begin{array}{l}\mathrm{Y}=0.19 \mathrm{X}+0.36 \\
\mathrm{R}^{2}=0.76\end{array}$ & $\begin{array}{l}\mathrm{Y}=0.27 \mathrm{X}-1.42 \\
\mathrm{R}^{2}=0.81\end{array}$ \\
\hline & 35 & $\begin{array}{l}\mathrm{Y}=1.18 \mathrm{X}+1.78 \\
\mathrm{R}^{2}=0.83\end{array}$ & $\begin{array}{l}\mathrm{Y}=0.04 \mathrm{X}+27.72 \\
\mathrm{R}^{2}=0.77\end{array}$ \\
\hline & 50 & $\begin{array}{l}\mathrm{Y}=0.82 \mathrm{X}+16.62 \\
\mathrm{R}^{2}=0.76\end{array}$ & $\begin{array}{l}\mathrm{Y}=0.04 \mathrm{X}+33.57 \\
\mathrm{R}^{2}=0.74\end{array}$ \\
\hline \multirow{3}{*}{ HDF \& L-HDF } & 20 & $\begin{array}{l}\mathrm{Y}=0.01 \mathrm{X}+0.42 \\
\mathrm{R}^{2}=0.74\end{array}$ & 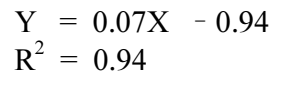 \\
\hline & 35 & $\begin{array}{l}Y=0.31 X-1.34 \\
R^{2}=0.76\end{array}$ & $\begin{array}{l}\mathrm{Y}=0.20 \mathrm{X}+3.97 \\
\mathrm{R}^{2}=0.96\end{array}$ \\
\hline & 50 & $\begin{array}{l}Y=1.60 X-4.84 \\
R^{2}=0.96\end{array}$ & $\begin{array}{l}\mathrm{Y}=0.03 \mathrm{X}+28.62 \\
\mathrm{R}^{2}=0.77\end{array}$ \\
\hline
\end{tabular}

ditions in flooring materials with temperatures of $50 \sim 60^{\circ} \mathrm{C}$. When the temperature is raised to this level, all the processes with a potential contribute to the formaldehyde emission, such as diffusion within a flooring material, desorption, evaporation and chemical reactions, are increased[7].

Myers showed[8] an exponential formaldehyde emission from wood-based products.
The emission from PB increased between the temperatures 23 and $40^{\circ} \mathrm{C}$, by the increasing factor of 5.2.

According to this result, some wood composites may contribute to the loading with VOC of indoor air due to the use of floor heating. Therefore, test temperature and time are important factors for the formaldehyde emission test. 
Effect of Temperature and Bake-out on Formaldehyde Emission from UF Bonded Wood Composites

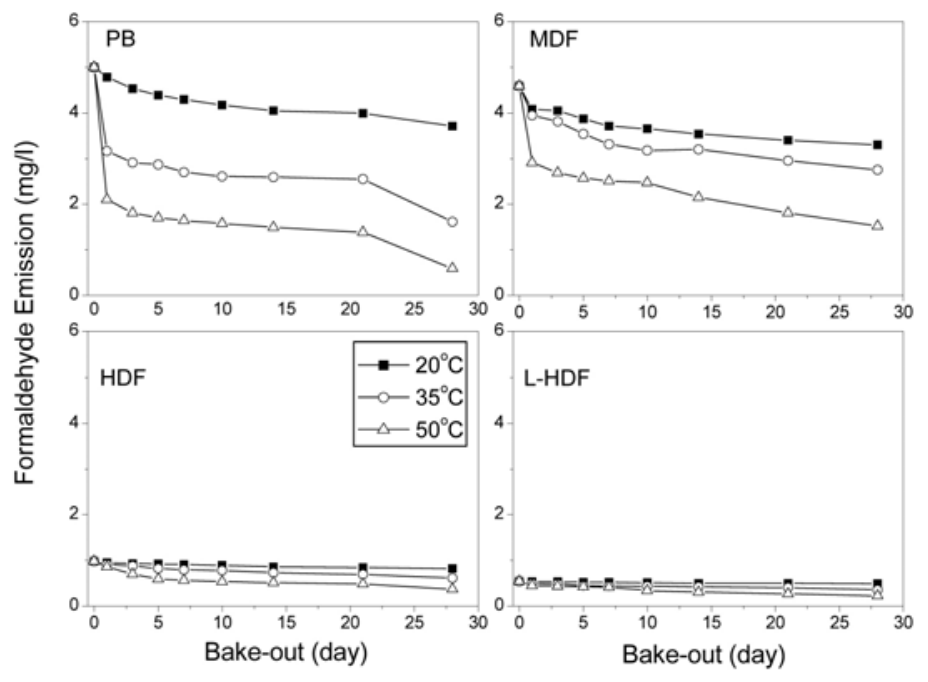

Fig. 6. Formaldehyde emission after 28-day bake-out of the composites at 20,35 , and $50^{\circ} \mathrm{C}$.

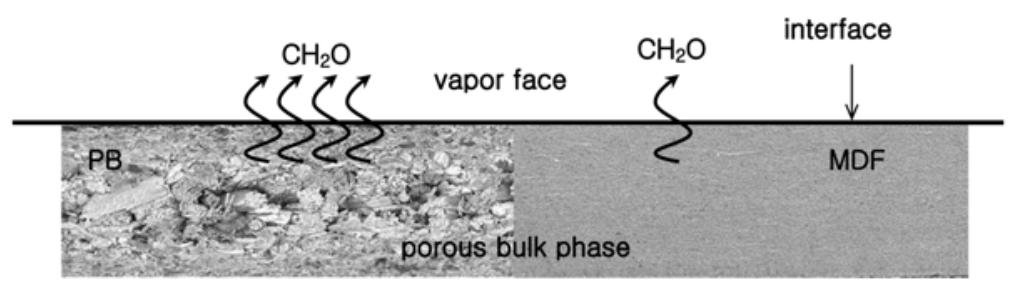

Fig. 7. The bulk-air interface at the edge section of $\mathrm{PB}$ and MDF.

In Figs. 1 4, the four composites showed different maximum times for the increasing rate of formaldehyde emission. For $\mathrm{PB}$ and $\mathrm{MDF}$ the maximum was achieved at $12 \mathrm{~h}$, while that of HDF and L-HDF was maximum at $24 \mathrm{~h}$ for $20^{\circ} \mathrm{C}$ test temperature. This result was influenced firstly by heat transmission and secondary by the density of the composites. The heat transmission of the lower density composites (PB and MDF) was lower than that of the higher density composites (HDF and L-HDF) at the same temperature.

Generally, formaldehyde emission decreased with increasing board density. Formaldehyde emission occurs at several stages in the compo- sites manufacturing process. The largest emission source is the drying of the composites, which may account for about $75 \%$ of the formaldehyde emission the composites manufacturing. The effect of board density on formaldehyde emission is complicated and may result from a combination of wood fiber or particle cell wall collapse[9], mat temperature and matvapor pressure during the composites manufacture processing. Higher platen pressure is needed to produce higher density composites, which causes more cell wall collapse. The composite density also affects the mat temperature distribution and vapor transportation in the mat. By comparing the mat temperature and vapor 
pressure distributions of composites with different densities, it was found that the maximum vapor pressure in the composite center and the composite center temperature both increased with increasing composite density. The effect of board density on formaldehyde emission resulted from the combined effect of the cell wall collapse, composite temperature and vapor pressure. There- fore, the formaldehyde emission rate of the finished product composites for indoor use was lower. In short, HDF and L-HDF were a lot of formaldehyde emission from the composites manufacturing process. And then, formaldehyde emission of HDF and L-HDF increased with longer test time and higher temperature than $\mathrm{PB}$ and MDF.

Fig. 5 and Table 1 shows correlation between the formaldehyde emission and temperature of composites. The composites were divided into two sub-groups according to the specific gravity: $\mathrm{PB}$ and MDF in the low density group, and HDF and L-HDF in the high density group.

The results divided two parts. One part is $6 \sim$ $24 \mathrm{~h}$ test duration and others $24 \sim 150 \mathrm{~h}$. The increasing rate of formaldehyde emission for $\mathrm{PB}$ \& MDF group was the highest during the $6 \sim$ $24 \mathrm{~h}$ duration at $35^{\circ} \mathrm{C}$. On the other hand, the formaldehyde demission for HDF \& L-HDF was the highest for $6 \sim 24 \mathrm{~h}$ duration at $50^{\circ} \mathrm{C}$.

The formaldehyde emission levels of the lower specific gravity composites were more affected by temperature. Temperature played an important role in the free formaldehyde emissions, either as an agent to extract and transport formaldehyde from the composite or as a heat conductor that changed the mean composite temperature.

According to the temperature profile of the composites during the test conditions (20, 35 and $50^{\circ} \mathrm{C}$ ), the formaldehyde emission were increased with increasing temperature under the experimental conditions.

\subsection{Effect of Bake-out on Form- aldehyde Emission}

The formaldehyde emission of the composites was measured at 20,35 and $50^{\circ} \mathrm{C}$. The results of the fitted curves are shown in Fig 6. The bake-out temperature exerted has a strong influence. The formaldehyde emissions from all composites decreased with increasing bake-out temperature and time.

Formaldehyde emission of control PB was $5.0 \mathrm{mg} / \ell$, which rapidly decreased over the bake-out time. After 28 days it was 3.7 $(-26.8 \%), 1.6(-67.8 \%)$ and $0.6 \mathrm{mg} / \ell(-82.2 \%)$ at 20,35 and $50^{\circ} \mathrm{C}$.

The reduction rate of formaldehyde emissionof $\mathrm{PB}$ was the highest rate in experiment composites under bake out condition. On the other hand, the formaldehyde emission of MDF was only slightly affected by $35^{\circ} \mathrm{C}$ bake-out temperature. After 10 days at $50^{\circ} \mathrm{C}$, the formaldehyde emission rapidly decreased.

A low formaldehyde emission was observed from $\mathrm{HDF}$ at $20^{\circ} \mathrm{C}$. The increase of temperature up to 30 and $50^{\circ} \mathrm{C}$ caused a reduction in the formaldehyde emission.

The trends of L-HDF, after 14 days at $35^{\circ} \mathrm{C}$, the emission was reduced by $22 \%(0.42 \mathrm{mg} / \ell)$ compared to that at $20^{\circ} \mathrm{C}(0.5)$. After 14 days at $50^{\circ} \mathrm{C}$, the emission was decreased by $44 \%$ $(0.3 \mathrm{mg} / \ell)$.

Since laminated on both sides with decorative paper of HDF (L-HDF), the exposure surface was smaller than HDF surface area.

Fig. 7 shows a porous bulk phase PB and MDF that emit formaldehyde into an adjoining air phase. Formaldehyde emission was higher from the edge of the PB than from the surface, and was affected by PB layer construction details such as particle geometry and size, porosity, and density.

The effect could be expected from a bake-out 
in relation to $\mathrm{PB}$. The relatively large decrease of the emission from 20 to $35^{\circ} \mathrm{C}$ was remarkable, as was the strong increase from 35 to $50^{\circ} \mathrm{C}$. After the bake-out at $50^{\circ} \mathrm{C}$ for 28 days, the formaldehyde concentration decreased by $88.2,66.9,62.2$ and $59.3 \%$ of the concentration before the bake-out for PB, MDF, HDF and L-HDF, respectively. On the other hand, even under $35^{\circ} \mathrm{C}$ for 28 days bake-out, the formaldehyde concentrations reduced $67.8 \%(\mathrm{~PB})$, $40.1 \%$ (MDF), $37.8 \%$ (HDF), and $35.2 \%$ (L-HDF) after the bake-out.

Temperature, air velocity and humidity are environmental parameters that affect volatile organic compounds (VOCs) emissions from building materials. The temperature variations did not have a significant effect on the emissions of volatile compounds with a lower boiling point but had a stronger effect on volatile compoundswith a higher boiling point[10]. To determine the effect of temperature, the emission of VOCs and carbonyl compounds from engineered flooring and laminate flooring were measured using a thermal extractor (TE), which was applied at 25,35 and $45^{\circ} \mathrm{C}$ for $30 \mathrm{~min}$. At $35^{\circ} \mathrm{C}$, the level of TVOC emission was more than double that at $25^{\circ} \mathrm{C}$. At 35 and $45^{\circ} \mathrm{C}$, the level of formaldehyde emission was more than two and five times of that at $25^{\circ} \mathrm{C}$, respectively[11].

According to the results of a few pilot studies, bake-out achieved a decrease of $60 \sim 94 \%$ in total VOC levels[12-14], although contradictory results have also been reported[15-17]. There are some limitations for the use of bake-out in practice such as material damage caused by excessive temperature and humidity changes, possible sorption effects, risks for odor and irritation complaints of inhabitants after the bake-out and the overall costs of the procedure $[4,13,18]$.

From the result of bake-out at $50^{\circ} \mathrm{C}$ after 14 days, formaldehyde emission grade of $\mathrm{PB}$ and MDF down $\mathrm{E}_{2}$ to $\mathrm{E}_{1}$, HDF and L-HDF down $\mathrm{E}_{1}$ to $\mathrm{E}_{0}$.

The reduction of formaldehyde emission observed fluctuating point about 7 days in bake out. Therefore, it is concluded that the bake-out procedure generally takes several days to one week at 35 or $50^{\circ} \mathrm{C}$ and is performed to reduce formaldehyde emission.

\section{CONCLUSIONS}

The results of free formaldehyde emission as measured by desiccator method depend board on the temperature. The formaldehyde emission rate increases with temperature and time. In the other cases, the general trend of the emission profile with increasing temperature is an increased initial emission, followed by an increased rate.

On average, the increasing of formaldehyde emission was increased 6 (PB), 5 (MDF), 8 (HDF), 14 (L-HDF) times with a $15^{\circ} \mathrm{C}$ increase in temperature from 20 to $35^{\circ} \mathrm{C}$. Formaldehyde emissions from wood composites could be expected to increase with increasing temperature.

From the result of bake-out at $50^{\circ} \mathrm{C}$ after 14 days, formaldehyde emission grade of $\mathrm{PB}$ and MDF down $E_{2}$ to $E_{1}, H D F$ and L-HDF down $E_{1}$ to $\mathrm{E}_{0}$.

The bake-out procedure demonstrated favorable potential to reduce formaldehyde concentrations from raw wood composites panels. Longer bake-out times may be necessary to achieve the desired reductions in formaldehyde concentrations. Because furnishings and building materials can vary widely from building to building, it is apparent that the bake-out treatment of several buildings must be studied under different conditions like temperature, duration, and ventilation rate before firm conclusions can be drawn. 
Since formaldehyde has much to do with temperature, the temperature within the building would be raised to $35^{\circ} \mathrm{C}$ to evaporate the free formaldehyde from the uncoated small size "fresh" panels. The reduction of formaldehyde emission observed fluctuating point about 7 days in bake-out treatment.

The results of this study could contribute to the material emission database, needed for the exposure assessment of the population. The results suggest are based on small samples, uncoated and E2 class, where the edges play a major role that a short bake-out period of one week in new or newly renovated buildings will be ineffective. It would be better to let the hazardous gas emit out as soon as possible before moving in. Residents are recommendedto bake out the house, opening the windows and turn on heater to evacuate harmful gas for some weeks before moving in.

\section{REFERENCES}

1. Van Der Wal, J. F., A. W. Hoogeveen, and P. Wouda. 1997. Indoor Air 7: 215 221.

2. Park, B. I., H. T. Seok, and K.-W. Kim. 1995. Air Conditioning and Refrigeration Engineering 24(6): $613 \sim 627$.

3. Song, G.-S. 2005. Energy and Buildings 37: 65 $\sim 75$ (2005).

4. Tuomainen, M., A. L. Pasanen, A. Tuomainen, J. Liesivuori, and P. Juvonen. 2001. Atmospheric Environment 35: 305 313.

5. Girman, J. R., L. E. Alevantis, G. C. Kulasingam, M. X. Petreas, and L. M. Webber. 1989. Environment International 15: 449 453.

6. Japanese Industrial Standard. 2001. JIS A 1460, Building boards determination of formaldehyde emission desiccator method, Japanese Industrial Standards Association.

7. Evaluation of VOC emissions from building products. 1997. Solid Flooring materials Euro- pean Collaborative Action Indoor Air Quality \& Its Impact on Man, Report No. 18, European Commission Joint Research Institute Environmental Institute.

8. Rybicky, J., J. Horst, and S. M. Kambanis. 1983. Forest Products Journal 33(9): 50 54.

9. Wolcott, M. P., F. A. Kamke, and D. A Dillard. 1990. Wood and Fiber Science 22(4): 345 361.

10. Sollinger, S., K. Levsen, and G. Wunsch, 1993. Atmospheric Environment 27B: 183 192.

11. Lee, Y. K. and H.-J. Kim. 2012. Building and Environment 53: 95 99.

12. Girman, J., L. Alevantis, G. Kulasingam, M. Petreas, and L. Webber. 1987. in Proceeding of the Fourth International Conference on Indoor Air Quality and Climate, Vol. 1. Institute for Water, Soil, and Air Hygiene, pp.22-26, Berlin, Germany.

13. Girman, J. R. 1987. In Proceeding of Problem Build- ings: Building-Associated Illness and the Sick Building Syndrome. Hanley \& Belfus, Inc., pp. 695-712, Philadelphia, USA.

14. Follin, T. 1997. In Proceedings of Healthy Buildings/IAQ'97, Vol. 3, Healthy Buildings/ IAQ'97, pp. 353-356. Washington, USA.

15. Bayer, C. W. 1990. In Proceedings of the Fifth International Conference on Indoor Air Quality and Climate, Vol. 3. Canada Mortgage and Housing Corporation, pp. 581 586 Ottawa.

16. Bayer, C. W. 1991. In Proceeding of Indoor Air Pollution: Radon, Bioaerosols, and VOCs. Lewis Publishers, Inc., pp. 101 113, Michigan, USA.

17. Offerman, F. J., S. A. Loiselle, G. Ander, and H. Lau. 1993. In Proceedings of the ASHRAE Conference IAQ'93. American Society of Heating, Refrigerating and Air-Conditioning Engineers, Inc., Philadelphia, USA.

18. Levin, H. 1989. In Proceeding of Problem Buildings: Building-Associated Illness and the Sick Building Syndrome. Hanley \& Belfus, Inc., pp. $667 \sim 669$, Philadelphia, USA. 